\title{
The acute effects of a lunch containing capsaicin on energy and substrate utilisation, hormones, and satiety
}

\author{
Astrid J. Smeets · Margriet S. Westerterp-Plantenga
}

Received: 2 July 2008/ Accepted: 30 January 2009/Published online: 24 February 2009

(c) The Author(s) 2009. This article is published with open access at Springerlink.com

\begin{abstract}
Background Addition of capsaicin to the diet has been shown to increase satiety and thermogenesis. The effects of capsaicin on ghrelin, peptide YY (PYY) and glucagon-like peptide 1 (GLP-1), in relation to changes in hunger and satiety are unknown.

Aim To test the acute effects of a lunch containing capsaicin on gut derived hormones (GLP-1, ghrelin, and PYY), energy expenditure (EE), substrate oxidation and satiety at lunch in the postprandial state.

Methods Thirty subjects (age: $31 \pm 14$ years, BMI: $23.8 \pm 2.8 \mathrm{~kg} / \mathrm{m}^{2}$ ) were studied twice in a crossover design. After 30 min resting on a bed, resting metabolic rate was measured by a ventilated hood system. Subsequently lunch (35\% of daily energy intake) was served. The two lunch conditions were: (1) lunch without capsaicin and (2) lunch with capsaicin (CAPS). The macronutrient composition (energy percentage) of the lunches was $60 \%$ carbohydrates, $10 \%$ protein and $30 \%$ fat. During $3 \mathrm{~h}$ after the lunch diet-induced thermogenesis was measured. Furthermore, anchored $100 \mathrm{~mm}$ visual analogue scales on the appetite profile were collected $(t=0,30,60,120,150,180$ and 240) and blood samples were taken for analysis of GLP-1, PYY, and ghrelin concentrations $(t=0,45,60$, 120, and 180).
\end{abstract}

\footnotetext{
A. J. Smeets $(\varangle) \cdot$ M. S. Westerterp-Plantenga

Department of Human Biology, Nutrition and Toxicology

Research Institute Maastricht (NUTRIM), Maastricht University,

P.O. Box 616, 6200 MD Maastricht, The Netherlands

e-mail: astrid.smeets@hb.unimaas.nl
}

A. J. Smeets - M. S. Westerterp-Plantenga

Top Institute Food and Nutrition, P.O. Box 557,

6700 AN, Wageningen, The Netherlands
Results Satiety and EE were not different after CAPS lunch as compared to the control lunch. Fifteen minutes after lunch CAPS lunch increased GLP-1 $(p<0.05)$ and tended to decrease ghrelin $(p=0.07)$ as compared to the control lunch. PYY responses were not different between the CAPS lunch and the control lunch.

Conclusions An acute lunch containing capsaicin had no effect on satiety, EE, and PYY, but increased GLP-1 and tended to decrease ghrelin.

Keywords Obesity - Red pepper - Postprandial · Thermogenesis

\section{Introduction}

The global increase of obesity and associated comorbidities urges for effective and satisfying treatments [31]. Obesity is the ultimate result of an imbalance between energy intake and energy expenditure (EE) [26]. Weight loss can be achieved by reducing energy intake and/or increasing EE. Research has been focussing on specific food components, which may have favourable effects on weight-loss, weight-maintenance, and metabolism. One of these specific food components is capsaicin, the pungent principle of hot red pepper. Capsaicin has been reported to have favourable effects on EE, fat oxidation, and appetite control [11, 13, $30,32,33]$. The effects of capsaicin on energy and lipid metabolism are associated with an increase in sympathetic nervous system activity [12, 13, 32, 33].

In a recent study we have shown that the satiating effect of capsaicin is present after gastrointestinal exposure, and is even more profound after the combination of sensory and gastrointestinal exposure [30]. The stimulatory effect of capsaicin is likely due to the involvement of a transient 
receptor potential vanilloid receptor 1 (TRPV1)-linked mechanism [5]. Capsaicin-sensitive primary afferent sensory nerves are found in the nerves innervating the whole gastrointestinal tract [10, 16, 17]. From predominantly animal studies we know that capsaicin may affect gastrointestinal physiology [15]. Interestingly, capsaicin was found to increase blood flow and secretion in the gastrointestinal tract $[3,19,20,25]$. Furthermore, capsaicinsensitive primary afferent sensory nerves have been suggested to be involved in the effects of nutrients on gutderived hormones, such as cholescystokinin, ghrelin, peptide YY (PYY), glucagon-like peptide 1 (GLP-1), and gastric motility and emptying in rats $[1,6,7,21]$. Intestinal TRPV1-positive, and thus capsaicin binding, nerves may play a role in the observed effects of capsaicin. Possibly through effects on local blood flow or through intrinsic neural pathways, which both may affect the exposure of the gut to nutrients (through intestinal motility), and the hormone release of adjacent hormone releasing intestinal cells [15]. Few studies have looked at the effects of capsaicin on gastrointestinal physiology, i.e., gastric emptying and isolated intestinal muscle strip relaxation, in humans $[8,18]$. Whether capsaicin affects the secretion of gut-derived hormones, and whether this is associated with the satiating effects of capsaicin is unknown. Therefore, the aim of this study was to test the acute effects of a lunch containing capsaicin on gut-derived hormones (GLP-1, ghrelin, and PYY). In addition, we investigated the acute effects of a meal containing capsaicin on EE, substrate oxidation and satiety at lunch in the postprandial state. We hypothesised that a single meal containing capsaicin compared with a single control meal might increase satiety, diet-induced thermogenesis (DIT), plasma PYY and GLP-1 concentrations, and fat oxidation, and decrease plasma ghrelin concentrations, and respiratory quotient (RQ).

\section{Subjects and methods}

\section{Subjects}

Thirty healthy subjects (19 women and 11 men) with a body mass index (BMI in $\mathrm{kg} / \mathrm{m}^{2}$ ) of $20-30$ and aged $18-$ 60 years were recruited by advertisements in local newspapers and on notice boards at Maastricht University. All subjects underwent a medical screening, and all were in good health, non-smokers, not using medication, and at most moderate alcohol users (less than 10 units a week). Eating behaviour was assessed using a validated Dutch translation of the TFEQ. Cognitive restrained and unrestrained eating behaviour (Factor 1), emotional eating and disinhibition (Factor 2), and the subjective feeling of hunger (Factor 3) were scored [27]. The baseline characteristics of the subjects are presented in Table 1. A written informed consent was obtained from all the participants. The Medical Ethics Committee of the Academic Hospital in Maastricht approved the study.

\section{Experimental sessions}

The study had a single blind, randomised, crossover design. The two tests were conducted at least 1 week apart. Subjects underwent two indirect calorimetry tests for the measurement of EE and substrate oxidation. On the morning before the test $(8: 00$ a.m.), the subjects received a subject-specific breakfast (milk-based drink with fruit and cereals called "Drinkontbijt", Campina, Woerden, Netherlands), which provided $15 \%$ of each subject's individual daily energy requirements. Subjectspecific daily energy requirements were calculated based on basal metabolic rate (BMR), which was calculated with the equation of Harris and Benedict [9]. The BMR was multiplied by an activity index of 1.5. After the breakfast, subjects were not allowed to eat or drink during the morning except water and one cup of coffee or tea without milk or sugar. One hour before the test lunch was served (11:00 a.m.), baseline EE and substrate oxidation were measured by means of an open-circuit, ventilatedhood system with subjects lying supine for at least 30 min. At 12:00 a.m. the subjects received a lunch, which they consumed within $30 \mathrm{~min}$ of one of two randomly assigned treatments: control lunch or the lunch supplemented with $1,030 \mathrm{mg}$ red pepper equivalent to 80,000 Scoville Heat Units (SHU) of capsaicin (Cayenne, Solaray, Park City, UT, USA). This dose of capsaicin was chosen based on our experiences concerning the highest tolerable dose in a previous study. Both lunches provided $35 \%$ of each subject's individual daily energy requirements, provided $10 \%$ of energy from protein, $60 \%$ of energy from carbohydrate, $30 \%$ of energy from fat, and consisted of pasta (Technical University of Budapest,

Table 1 Subject characteristics $(n=30)$

\begin{tabular}{lc}
\hline & Value \\
\hline Age (years) & $31 \pm 14$ \\
Body weight $(\mathrm{kg})$ & $72 \pm 12$ \\
Height $(\mathrm{m})$ & $1.73 \pm 0.09$ \\
BMI $\left(\mathrm{kg} / \mathrm{m}^{2}\right)$ & $23.8 \pm 2.8$ \\
Body fat $(\%)$ & $25.6 \pm 8.8$ \\
Dietary restraint $^{\mathrm{a}}$ & $4.3 \pm 2.6$ \\
\hline
\end{tabular}

All values are mean $\pm \mathrm{SD}$

${ }^{\text {a }}$ Factor 1 (dietary restraint) of the Three-Factor Eating Questionnaire was used 
Department of Biochemistry and Food Technology, Budapest, Hungary), sausages (Matforsk, Ås, Norway), and tomato sauce (Heinz, Elst, The Netherlands). The spiciness of the meal with capsaicin was well tolerated by all subjects. Post-lunch EE and substrate oxidation were measured for $210 \mathrm{~min}$ after ingestion of the lunch.

\section{Energy expenditure and substrate oxidation}

On the test days, baseline and post-lunch EE and substrate oxidation were measured with an open-circuit, ventilatedhood system with the subjects lying supine [24]. Gas analysis was performed by a paramagnetic $\mathrm{O}_{2}$ analyser (OmniCal type 1155B; Crowborough, Sussex, UK) and an IR $\mathrm{CO}_{2}$ analyser (OmniCal type 1520/1507). EE was calculated using Brouwer's formula [2]. The RQ was calculated as $\mathrm{CO}_{2}$ produced $/ \mathrm{O}_{2}$ consumed. Carbohydrate, fat, and protein oxidation were calculated from the measurements of oxygen consumption, carbon dioxide production, and urinary nitrogen excretion by using the formula of Brouwer [2]. Urine samples were collected from the first void after the start of the test day (11:00 a.m.) until the last void on the test day $(4: 00 \mathrm{pm})$. Subjects voided their bladder before the start of the test day (before 11:00 a.m.). Samples were collected in containers with $10 \mathrm{ml} \mathrm{H}_{2} \mathrm{SO}_{4}$ to prevent nitrogen loss through evaporation. Volume and nitrogen concentration were measured, the latter with a nitrogen analyser (CHN-O-Rapid; Heraeus, Hanau, Germany).

\section{Blood sampling}

One hour before the lunch was served (11:00 a.m.), a polytetrafluoroethylene catheter was placed in the antecubital vein for blood sampling. During each test day, five blood samples (at 0, 45, 60, 120, and $180 \mathrm{~min}$ after lunch) were taken for measurement of plasma ghrelin, GLP-1, and PYY concentrations. Blood samples were collected in tubes kept on ice and containing EDTA to prevent clotting. Plasma was obtained by centrifugation $\left(4^{\circ} \mathrm{C}\right.$, 3,000 rpm, $10 \mathrm{~min}$ ) and stored at $-80{ }^{\circ} \mathrm{C}$ until analysed. Plasma concentrations of active ghrelin were measured by RIA (Linco Research Inc., St. Charles, Missouri, USA). Plasma active ghrelin concentrations were measured in acidified plasma with $50 \mu \mathrm{l}$ of $1 \mathrm{~N} \mathrm{HCl}$ and addition of $10 \mu \mathrm{l}$ of phenylmethylsulfonyl fluoride (PMSF) per $1 \mathrm{ml}$ of plasma. Sensitivity of the RIA assay was $7.8 \mathrm{pg} / \mathrm{ml}$ and the difference between duplicate results of a sample was less than $10 \% \mathrm{CV}$. The specificity for human ghrelin was $100 \%$. Plasma active GLP-1 samples were analysed using ELISA (EGLP-35K; Linco Research Inc., St. Charles, Missouri, USA). Plasma active GLP-1 concentrations were measured in plasma after addition of $10 \mu \mathrm{l}$ DPP-IV inhibitor per millilitre of blood. Sensitivity of the ELISA assay was $2 \mathrm{pM}$, and the difference between duplicate results of a sample was less than $10 \% \mathrm{CV}$. The specificity for active GLP-1 was $100 \%$. PYY was measured with a specific and sensitive radioimmunoassay, which measures both the full length (PYY1-36) and the fragment (PYY336) (Linco Research Inc., St. Charles, MO, USA). Plasma PYY concentrations were measured in plasma after addition of Aprotinin at a final concentration of $500 \mathrm{KIU} /$ $\mathrm{mL}$ of blood. Sensitivity of the PYY RIA assay was $10 \mathrm{pg} / \mathrm{ml}$ and the difference between duplicate results of a sample was less than $10 \% \mathrm{CV}$. The specificity for human PYY was $100 \%$.

\section{Appetite profile}

Appetite profile was measured with the use of anchored $100-\mathrm{mm}$ visual analogue scales (VAS). During each testday these questionnaires were completed just before the lunch $(t=0)$, and at 30, 60, 90, 120, 150, 180 and $240 \mathrm{~min}$. The questions were, "How hungry are you?" and "How satiated are you?" and were anchored by "not at all" and "very."

\section{Body composition}

Body composition was measured by using the deuterium dilution technique. $\mathrm{A}{ }^{2} \mathrm{H}_{2} \mathrm{O}$ dilution was used to measure total body water (TBW). The subjects were asked to collect a urine sample in the evening just before drinking the deuterium-enriched water solution. After ingestion of this solution, the subjects went to bed and no additional consumption was allowed for this period. Ten hours after drinking the water solution, another urine sample was collected. The dilution of the deuterium isotope is a measure of the TBW of the subject. Deuterium was measured in the urine samples with an isotope ratio mass spectrometer (VG-Isogas Aqua Sira; VG Isogas, Middlewich, England). TBW was obtained by dividing the measured deuterium dilution space by 1.04. Fat-free mass (FFM) was calculated by dividing TBW by the hydration factor 0.73. Fat mass (FM) was determined as BW-FFM [23, 28, 29].

\section{Statistical analysis}

Data are presented as mean \pm SD unless otherwise indicated. Differences between means were analysed by Student's $t$ test. Regression analyses were performed to determine the relations between selected variables. All statistical tests were performed by using Statview SE Graphics software (version 4.5; Abacus Concepts Inc., Berkeley, CA, USA). 


\section{Results}

Energy expenditure and substrate oxidation

Baseline EE did not differ before the CAPS lunch $(4.87 \pm 0.72 \mathrm{~kJ} / \mathrm{min})$ and control lunch $(4.77 \pm 0.81 \mathrm{~kJ} /$ min). The increase in post-lunch after the CAPS lunch $(0.62 \pm 0.28 \mathrm{~kJ} / \mathrm{min})$ did not differ from the control lunch $(0.72 \pm 0.22 \mathrm{~kJ} / \mathrm{min})$. Total post-lunch $\mathrm{EE}$ above baseline EE over $210 \mathrm{~min}$ after the CAPS lunch $(133.7 \pm 58.3 \mathrm{~kJ})$ did not differ from the control lunch $(151.34 \pm 47.09 \mathrm{~kJ})$. Total post-lunch EE above baseline EE over $210 \mathrm{~min}$ as percentage of the energy content of the lunch after the CAPS lunch $(3.9 \pm 1.4 \%)$ did not differ from the control lunch $(4.3 \pm 1.2 \%)$ either.

Respiratory quotient did not differ between the CAPS $(0.85 \pm 0.05)$ and the control $(0.86 \pm 0.04)$ treatments. Non-protein RQ did not differ between the CAPS $(0.86 \pm 0.05)$ and control $(0.87 \pm 0.05)$ treatments. Substrate oxidation was not different in the CAPS condition from the control condition (protein oxidation CAPS: $15.2 \pm 4.7 \mathrm{~g}$, control: $16.9 \pm 6.2 \mathrm{~g}$, carbohydrate oxidation CAPS: $34.4 \pm 12.8 \mathrm{~g}$, control: $37.3 \pm 12.4 \mathrm{~g}$, fat oxidation CAPS: $15.2 \pm 7.2 \mathrm{~g}$, control: $13.2 \pm 6.4 \mathrm{~g}$ ).

\section{Blood parameters}

The plasma hormone concentrations did not differ between the two treatments at baseline. Changes in hormone concentrations in response to the lunches are expressed as the change from baseline. Plasma GLP-1 responses were higher at $t=45 \mathrm{~min}$ in the CAPS condition than in the control condition ( $p<0.05$, Fig. 1). The AUC of plasma GLP-1 response did not differ after the CAPS lunch $(221 \pm 91 \mathrm{pM} \mathrm{h})$ and the control lunch (191 $\pm 94 \mathrm{pM} \mathrm{h})$.

Plasma active ghrelin response tended to be lower at $t=45 \mathrm{~min}$ in the CAPS condition compared to in the

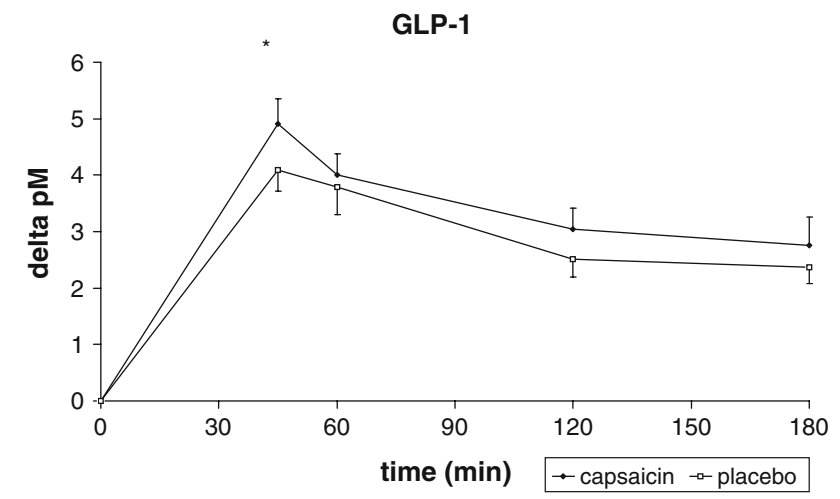

Fig. 1 Mean $( \pm$ SEM) changes in GLP-1 plasma concentrations from baseline for the capsaicin $(n=30)$ and control $(n=30)$ lunch. $* p<0.05$
Ghrelin

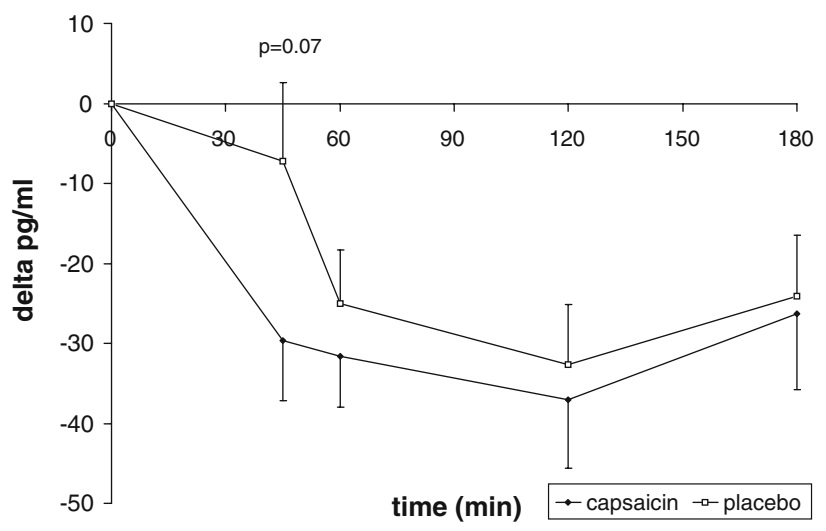

Fig. 2 Mean $( \pm$ SEM) changes in active ghrelin plasma concentrations from baseline for the capsaicin $(n=30)$ and control $(n=30)$ lunch

control condition ( $p<0.07$, Fig. 2). The AUC of plasma active ghrelin response did not differ after the CAPS lunch $(-1,869 \pm 2,281 \mathrm{pg} / \mathrm{ml} \mathrm{h})$ and the control lunch $(-1,334 \pm 1,886 \mathrm{pg} / \mathrm{ml} \mathrm{h})$.

Plasma PYY responses did not differ at any of the measured time points after the CAPS and control lunch (Fig. 3). The AUC of plasma PYY response did not differ after the CAPS lunch $(139 \pm 1,107 \mathrm{pg} / \mathrm{ml} \mathrm{h})$ and the control lunch $(259 \pm 880 \mathrm{pg} / \mathrm{ml} \mathrm{h})$.

Appetite profile

Satiety VAS scores did not differ at any of the measured time points between the CAPS and control lunch (Fig. 4). AUC satiety VAS score did not differ after the CAPS and control lunch (Fig. 4). Satiety VAS scores were not correlated with plasma GLP-1, ghrelin, and PYY concentrations at any time-point or when expressed as AUC.

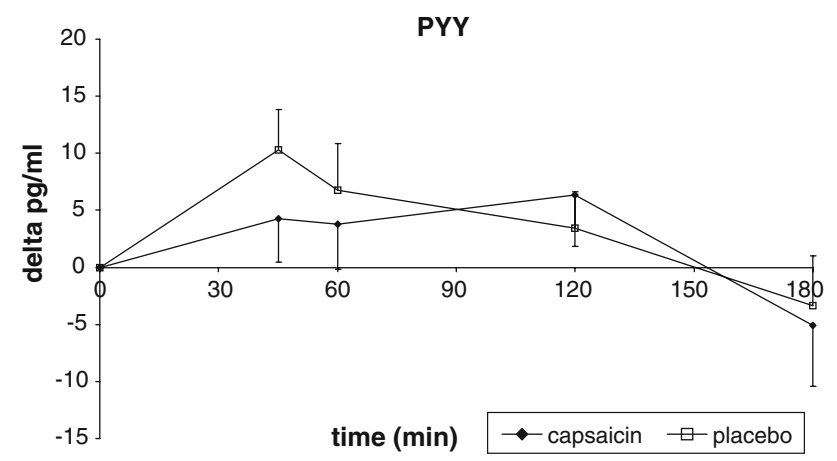

Fig. 3 Mean $( \pm$ SEM) changes in PYY plasma concentrations from baseline for the capsaicin $(n=30)$ and control $(n=30)$ lunch 


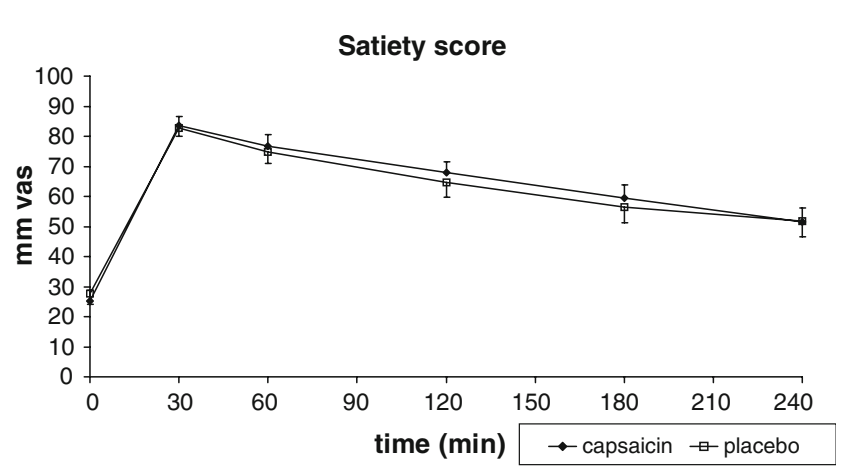

Fig. 4 Mean $( \pm$ SEM) satiety ratings measured with the use of an anchored $100-\mathrm{mm}$ visual analogue scale for the capsaicin $(n=30)$ and control $(n=30)$ lunch

\section{Discussion}

In the present study, a single meal with $1,030 \mathrm{mg}$ red pepper equivalent to $80,000 \mathrm{SHU}$ of capsaicin in the postprandial phase, did not affect subjective feelings of satiety, DIT, substrate oxidation, and plasma PYY responses for a period of $3 \mathrm{~h}$ as compared to a control meal. Over a short period of time, i.e., $15 \mathrm{~min}$, a single meal with capsaicin in the postprandial phase, significantly increased plasma GLP-1 concentrations and tended to decrease plasma ghrelin concentrations as compared to a control meal.

In a study by Yoshioka, the addition of $30 \mathrm{mg}$ capsaicin to a high-fat breakfast and a high-carbohydrate breakfast significantly decreased prospective food consumption at lunch [32]. Furthermore, desire to eat as well as hunger significantly decreased after the high-fat breakfast with capsaicin. An important difference between the latter study and our study, which may explain the differences in satiety related outcomes, is that we tested the addition of capsaicin at lunch.

Although physiologically important, the postprandial state may have masked the differences in feelings of satiety after the CAPS compared to the control meal. In a recent study we observed that subjective feelings of satiety were significantly higher after capsaicin supplementation over 2 days compared to placebo, which suggests that the effect of capsaicin on subjective feelings of satiety may need to build up [30].

In the present study, we observed no differences in DIT between the CAPS and the control condition. We hypothesised that DIT would be higher after the CAPS meal compared to after the control meal. Capsaicin is perceived as a hot substance [22]. Because the ingestion of hot substances can lead to an increase in body temperature, feedback mechanisms are activated to lower body temperature, such as blood vessel dilatation and sweating. The greater heat loss, due to blood vessel dilatation and sweating, after capsaicin ingestion may contribute to a higher DIT. Again, in the present study the postprandial state may have masked the effect of CAPS on DIT. The previously observed small and short effect of capsaicin on $\mathrm{EE}$, in the post-absorptive state, may have been too small to be distinguished during the postprandial state [33].

We observed no differences in substrate oxidation between the CAPS and control condition. Capsaicin has been reported to increase carbohydrate oxidation over the short term (after one breakfast exposure) and to increase fat oxidation over the long term (in fasted state after 3 months exposure) [14, 33].

Fifteen minutes after the CAPS lunch, plasma GLP-1 concentrations were significantly increased, and there was a trend for plasma ghrelin concentrations to be decreased compared to after the control lunch. Capsaicin was found to increase gastric emptying in a study by Debreceni et al. [4]. In the present study, increased gastric emptying after the CAPS lunch may have resulted in earlier exposure of the small intestine to nutrients, which subsequently may have led to a stronger effect on gut-derived hormones over a short period of time. As far as we know, no other human studies have looked at the effects of CAPS supplementation on gut-derived hormones. Therefore, more research is needed to investigate the mechanisms behind the possible effects of capsaicin on gut-derived hormones.

In comparison with other studies we observed no acute effects of CAPS on satiety, DIT, substrate oxidation, and plasma PYY responses for a period of $3 \mathrm{~h}$. Over a short period of time, i.e., 15 min, a single meal with capsaicin in the postprandial phase, significantly increased plasma GLP-1 concentrations and tended to decrease plasma ghrelin concentrations.

The present results should be interpreted with caution, because this study was conducted at lunch in the postprandial state. Most studies on single meals containing CAPS have been conducted at breakfast in the postabsorptive state, which make them difficult to compare with the present study.

The data of the present paper indicate that the CAPS supplementation of one meal in a postprandial state has no effects on substrate utilisation, appetite feelings and PYY responses. However, the observed effects of CAPS on GLP-1 and ghrelin responses warrant more intensive research on the possible eating behaviour-related effects of capsaicin.

Acknowledgments We gratefully acknowledge Helene Reinbach, Maartje Spetter, Rick Hursel, Tine Horsten and Lizette den Hollander for their assistance. AJS designed the experiment, collected and analysed the data, and wrote the manuscript. MSW-P designed the experiment, helped analyse the data and write the manuscript, and supervised the project. None of the authors had any financial or personal interest in any company or organisation sponsoring the 
research. The project was funded by DiOGenes (Contract no. FP6513946). Some of these data were presented at the European Winter Conference on Brain Research, 2008.

Open Access This article is distributed under the terms of the Creative Commons Attribution Noncommercial License which permits any noncommercial use, distribution, and reproduction in any medium, provided the original author(s) and source are credited.

\section{References}

1. Ahren B (2004) Sensory nerves contribute to insulin secretion by glucagon-like peptide-1 in mice. Am J Physiol Regul Integr Comp Physiol 286:R269-R272

2. Brouwer E (1957) On simple formulae for calculating the heat expenditure and the quantities of carbohydrate and fat oxidized in metabolism of men and animals, from gaseous exchange (Oxygen intake and carbonic acid output) and urine-N. Acta Physiol Pharmacol Neerl 6:795-802

3. Chen RY, Li DS, Guth PH (1992) Role of calcitonin gene-related peptide in capsaicin-induced gastric submucosal arteriolar dilation. Am J Physiol 262:H1350-H1355

4. Debreceni A, Abdel-Salam OM, Figler M, Juricskay I, Szolcsanyi J, Mozsik G (1999) Capsaicin increases gastric emptying rate in healthy human subjects measured by 13C-labeled octanoic acid breath test. J Physiol Paris 93:455-460

5. Eldershaw TP, Colquhoun EQ, Bennett KL, Dora KA, Clark MG (1994) Resiniferatoxin and piperine: capsaicin-like stimulators of oxygen uptake in the perfused rat hindlimb. Life Sci 55:389-397

6. Fu-Cheng X, Anini Y, Chariot J, Castex N, Galmiche JP, Roze C (1997) Mechanisms of peptide YY release induced by an intraduodenal meal in rats: neural regulation by proximal gut. Pflugers Arch 433:571-579

7. Fukuda H, Mizuta $Y$, Isomoto H, Takeshima F, Ohnita K, Ohba K, Omagari K, Taniyama K, Kohno S (2004) Ghrelin enhances gastric motility through direct stimulation of intrinsic neural pathways and capsaicin-sensitive afferent neurones in rats. Scand J Gastroenterol 39:1209-1214

8. Giuliani S, Turini D, Barbanti G, Maggi CA (1991) Ruthenium red as a selective capsaicin antagonist of the motor response to capsaicin in the human isolated ileum. Eur J Pharmacol 196:331333

9. Harris JA, Benedict FG (1918) A Biometric Study of Human Basal Metabolism. Proc Natl Acad Sci USA 4:370-373

10. Holzer-Petsche U, Seitz H, Lembeck F (1989) Effect of capsaicin on gastric corpus smooth muscle of the rat in vitro. Eur J Pharmacol 162:29-36

11. Kawabata F, Inoue N, Yazawa S, Kawada T, Inoue K, Fushiki T (2006) Effects of CH-19 sweet, a non-pungent cultivar of red pepper, in decreasing the body weight and suppressing body fat accumulation by sympathetic nerve activation in humans. Biosci Biotechnol Biochem 70:2824-2835

12. Kawada T, Sakabe S, Watanabe T, Yamamoto M, Iwai K (1988) Some pungent principles of spices cause the adrenal medulla to secrete catecholamine in anesthetized rats. Proc Soc Exp Biol Med 188:229-233

13. Kawada T, Watanabe T, Takaishi T, Tanaka T, Iwai K (1986) Capsaicin-induced beta-adrenergic action on energy metabolism in rats: influence of capsaicin on oxygen consumption, the respiratory quotient, and substrate utilization. Proc Soc Exp Biol Med 183:250-256
14. Lejeune MP, Kovacs EM, Westerterp-Plantenga MS (2003) Effect of capsaicin on substrate oxidation and weight maintenance after modest body-weight loss in human subjects. Br J Nutr 90:651-659

15. Leung FW (2008) Capsaicin-sensitive intestinal mucosal afferent mechanism and body fat distribution. Life Sci 83:1-5

16. Maggi CA, Manzini S, Giuliani S, Santicioli P, Meli A (1986) Extrinsic origin of the capsaicin-sensitive innervation of rat duodenum: possible involvement of calcitonin gene-related peptide (CGRP) in the capsaicin-induced activation of intramural non-adrenergic non-cholinergic neurons. Naunyn Schmiedebergs Arch Pharmacol 334:172-180

17. Maggi CA, Meli A, Santicioli P (1987) Four motor effects of capsaicin on guinea-pig distal colon. Br J Pharmacol 90:651-660

18. Maggi CA, Theodorsson E, Santicioli P, Patacchini R, Barbanti G, Turini D, Renzi D, Giachetti A (1990) Motor response of the human isolated colon to capsaicin and its relationship to release of vasoactive intestinal polypeptide. Neuroscience 39:833-841

19. Manzini S, Perretti F (1988) Vascular effects of capsaicin in isolated perfused rat mesenteric bed. Eur J Pharmacol 148:153159

20. Myers BM, Smith JL, Graham DY (1987) Effect of red pepper and black pepper on the stomach. Am J Gastroenterol 82:211-214

21. Raybould HE, Tache Y (1988) Cholecystokinin inhibits gastric motility and emptying via a capsaicin-sensitive vagal pathway in rats. Am J Physiol 255:G242-G246

22. Rolls ET, Verhagen JV, Kadohisa M (2003) Representations of the texture of food in the primate orbitofrontal cortex: neurons responding to viscosity, grittiness, and capsaicin. J Neurophysiol 90:3711-3724

23. Schoeller DA, van Santen E, Peterson DW, Dietz W, Jaspan J, Klein PD (1980) Total body water measurement in humans with $18 \mathrm{O}$ and 2H labeled water. Am J Clin Nutr 33:2686-2693

24. Schoffelen PF, Westerterp KR, Saris WH, Ten Hoor F (1997) A dual-respiration chamber system with automated calibration. J Appl Physiol 83:2064-2072

25. Solanke TF (1973) The effect of red pepper (Capsicum frutescens) on gastric acid secretion. J Surg Res 15:385-390

26. Stunkard AJ (1996) Current views on obesity. Am J Med 100:230-236

27. Stunkard AJ, Messick S (1985) The three-factor eating questionnaire to measure dietary restraint, disinhibition and hunger. J Psychosom Res 29:71-83

28. van Marken Lichtenbelt WD, Westerterp KR, Wouters L (1994) Deuterium dilution as a method for determining total body water: effect of test protocol and sampling time. Br J Nutr 72:491-497

29. Westerterp KR, Wouters L, van Marken Lichtenbelt WD (1995) The Maastricht protocol for the measurement of body composition and energy expenditure with labeled water. Obes Res 3(Suppl 1):49-57

30. Westerterp-Plantenga MS, Smeets A, Lejeune MP (2005) Sensory and gastrointestinal satiety effects of capsaicin on food intake. Int J Obes (Lond) 29:682-688

31. WHO (2000) Obesity: preventing and managing the global epidemic. Report of a WHO consultation. World Health Organ Tech Rep Ser 894:i-xii, 1-253

32. Yoshioka M, St-Pierre S, Drapeau V, Dionne I, Doucet E, Suzuki M, Tremblay A (1999) Effects of red pepper on appetite and energy intake. Br J Nutr 82:115-123

33. Yoshioka M, St-Pierre S, Suzuki M, Tremblay A (1998) Effects of red pepper added to high-fat and high-carbohydrate meals on energy metabolism and substrate utilization in Japanese women. Br J Nutr 80:503-510 